\title{
Anatomical Variation of Extra-Hepatic Biliary Tree and Vasculature Encountered During Laparoscopic Cholecystectomy
}

\author{
Shubhrashankha Sen ${ }^{1}$, Saurabh Goel², Madhubala Gaur ${ }^{3}$ \\ ${ }^{1}$ Post Graduate III' year, ${ }^{2}$ Professor, Department of Surgery, Saraswathi Institute of Medical Sciences Hapur \\ (U.P), ${ }^{3}$ Professor, Department of Surgery, Saraswathi Institute of Medical Sciences Hapur (U.P)
}

\begin{abstract}
Introduction: Variations in Extra-hepatic biliary tract are noticed. The common variations are intrahepatic union of right and left hepatic ducts, accessory hepatic ducts, different mode of termination of common hepatic duct, cystic duct and common bile duct.

Objective: To identify the Variations in the Extra-hepatic Biliary tree, which comprises of Right and Left Hepatic duct, Cystic Duct, Common Hepatic Duct, Common Bile Duct and Gall Bladder.

Materials and Methods: This study was conducted at Saraswathi institute of medical sciences(HAPUR,U.P) during the period between October 2017 to September 2019. A total of 200 patients reporting with gall bladder disease was recruited in the study in whom laparoscopic cholecystectomy was attempted.

Results: Overall, among 200 patients, a total of 50 patients had some amount of anatomical variations. Around $10 \%$ patients showed cystic duct variations, $18 \%$ showed extra-hepatic biliary tree variations, and another $7 \%$ patients showed arterial variations.

Conclusion: We found Around 10\% patients (one-fourth) showed cystic duct variations, $18 \%$ showed extrahepatic biliary tree variations, and another $7 \%$ patients showed arterial variations which is comparable and analogous to previous incidence rate.
\end{abstract}

Keywords: common bile duct, biliary tree, cholecystectomy

\section{Introduction}

Cholelithiasis or presence of calcified stones in the Gall Bladder, is the most common biliary pathology. Gallstones are present in 10 to $15 \%$ of the general population and asymptomatic in the majority $(>80 \%)^{(1,2)}$. The prevalence of gallstone varies widely in different parts of the world. In India it is estimated to be around $4 \%$.

\section{Corresponding Author:}

\section{Dr. Shubhrashankha Sen}

Post Graduate III ${ }^{\text {rd }}$ year, Department of SURGERY

Saraswathi Institute of Medical Sciences, Hapur (U.P)

Harypol278@gmail.com, Mob.: 9464780122
An epidemiological study showed that North Indians has 7 times higher occurrence of gallstones as compared to South Indians. Changing incidence in India is mainly attributed to westernization and availability of investigation that is ultrasound in both rural and urban areas and due to change in socioeconomic structure ${ }^{(3)}$. Cholelithiasis is rare in the first two decades. Incidence gradually increases after 21 years and reaches its peak in 5th Laparoscopic cholecystectomy has become the gold standard in the treatment of Gall stone disease and is replacing open cholecystectomy. The rate of conversion from laparoscopic cholecystectomy to open cholecystectomy is 5 to $10 \%{ }^{(5)}$.

Anatomical variations in extra-hepatic biliary tree and vasculature are one of the most common reasons 
for such iatrogenic injuries. Therefore, the laparoscopic surgeon should have knowledge of the anatomical variations of arterial and biliary tree. Incorrect surgery can lead to Cystic artery bleeding, injury to the extrahepatic bile duct or intra-abdominal organs needing conversion to open surgery and further morbidity. Many studies reported that the incidence of biliary anomalies varies from 15 to 66 percent ${ }^{(10,11,12)}$.

This study aims at describing some anatomical variations of the extra hepatic biliary system that face the surgeon during cholecystectomy and determine the type and frequency of each anomaly.

\section{Material and Method}

The present study was a randomized and prospective study conducted in Saraswathi Institute of Medical Sciences and Hospital, Hapur (UP), India from $1^{\text {st }}$ October 2017 to $30^{\text {th }}$ September2019 and was carried out on the patients being admitted to the Department of General Surgery, through Out-patient department / Emergency.

A total of 200 patients reporting with gall bladder disease was recruited in the study. In the present series, patients of Cholelithiasis were admitted for cholecystectomy (with Ultrasound whole abdomen proven diagnosis of cholelithiasis or calculus cholecystitis) in Saraswathi Institute of Medical Sciences Hapur were considered, in whom laparoscopic cholecystectomy was attempted.

Between October 2017 and September 2019, prospective evaluation of 200 patients treated by laparoscopic cholecystectomy for gall stone diseases was done.Diagnosis of gall stone disease was confirmed by ultrasound whole abdomen in all patients prior to surgery.

Statistical analysis was performed using SPSS (Statistical Package for the Social Sciences) for Windows (version 21.0). Categorical variables were described as frequency (percentage), mean \pm standard deviation was used for continuous parameters. Differences between two groups were compared by the Student $\mathrm{T}$ test. For non-parametric variables, the data are presented as median (min-max). In this case, the nonparametric Mann-Whitney test was used for statistical comparisons.
Categorical variables were compared between two or more groups using the Chi-square test. For all analyses, a two-tailed p-value of $<0.05$ was considered statistically significant.

\section{Results}

The study was carried out among 200 patients voluntarily consenting to be a part of the study. These patients were were diagnosed with Gall Stone disease requiring cholecystectomy with no further severe complications such as cancer and being admitted to the Department of General Surgery, Saraswati Institute of Medical Sciences and Hospital, Hapur (Uttar Pradesh).

The age wise distribution of study participants showed that majority of them was in the age group of 21-30 years. The mean age of the study group was $37.8+11.4$ years $($ mean + s.d. $)$ and range $=17-60$ years . The gender wise distribution of study participants showed that majority of them were females $(85 \%)$ and $15 \%$ were males.

Overall, among 200 patients, a total of 50 patients had some amount of anatomical variations. Around 10\% patients showed cystic duct variations, $18 \%$ showed extra-hepatic biliary tree variations, and another $7 \%$ patients showed arterial variations.

Main findings of current study confirmed that the detailed information of the boundaries and contents of hepatobiliary triangle and its variable ductal and vascular patterns is of huge significance for the diagnostic and therapeutic success as it makes surgical approaches more focused and technically perfect.

Around 10\% patients (one-fourth) showed cystic duct variations, $18 \%$ showed extra-hepatic biliary tree variations, and another 7\% patients showed arterial variations which is comparable and analogous to previous incidence rate.

Cystic Duct: The present study had $10 \%$ cases of Cystic Duct anomalies out of 200, which is slightly higher in comparison to the Khamiso et al and Hasan et al study but lower in comparison to Lutfi et al study.

Calot's lymph node: The present study had 13 cases of Calot's Node anomaly, which is lower in comparison to previous studies. A total of $6.5 \%$ people had variation 
in lymph node position. Percentages of cystic lymph node variations included cystic lymph node antrolateral to cystic duct, cystic lymph node posterior to cystic duct and cystic lymph node outside hepatobiliary triangle.

Cystic Artery: The present study showed 7\%cases of Cystic Artery anomaly out of 200 which is comparable to various study and almost similar to Khamiso (2010) study. Accessory Cystic Artery and Moynihan's hump were also among the variations found in this study.

All subjects had single gall bladder present inferior to right lobe of liver with normal fundus and body. However, 92\% people had pear shaped gall bladder and $5 \%$ had flask shaped GB. Anatomy of the extrahepatic biliary tree is of great importance to the surgeon since this tree is one of the common sites of anatomical variations besides being one of the most common sites for surgical procedures.

\section{Discussion}

Ever since the introduction by Philippe Mouret in France, laparoscopic cholecystectomy is now gold standard for the management of symptomatic gallstones disease ${ }^{(53)}$. It is now offered to all corners with a success rate of $99 \%$. Exposure of hepatobiliary triangle remained main domain of current research work. The current study denotes higher incidences of normal cystic arteries and lower incidence of normal cystic duct compared to global ranges (Table-1).

Table 1: Comparison of Total Variations

\begin{tabular}{|l|l|l|l|l|l|}
\hline Studies: & $\begin{array}{l}\text { Present } \\
\text { Study }\end{array}$ & Khamiso et al (2010) & $\begin{array}{l}\text { Hasan et al } \\
\mathbf{( 2 0 1 3 )}\end{array}$ & $\begin{array}{l}\text { Lutfi et al } \\
\mathbf{( 2 0 1 3 )}\end{array}$ & Masroor et al (2016) \\
\hline Total Variations & $25 \%$ & $24.66 \%$ & $15.2 \%$ & $54 \%$ & - \\
\hline Cystic Duct & $10 \%$ & $4.33 \%$ & $4.4 \%$ & $12 \%$ & - \\
\hline Arterial & $7 \%$ & $20.33 \%$ & $8 \%$ & $40 \%$ & $7.6 \%$ \\
\hline Gall Bladder & $8 \%$ & - & $1.6 \%$ & $2 \%$ & - \\
\hline
\end{tabular}

Another study by Hasan et al (2013) reported incidence of $15.2 \%$ (63), while it was observed to be lower by Philippo et al (2008) (8.8\%) and Cochoeira et al (2012) (7.3\%) ${ }^{(64,65)}$. In this study, we found abnormal anatomy in $18 \%$ of the cases (including change in morphology of associated structures), which is comparable to other previous studies.

\begin{tabular}{|l|l|}
\hline Studies & Extra-Hepatic Biliary tree abnormality (\%) \\
\hline Present Study & 18 \\
\hline Hasan et al. (2013) & 15.2 \\
\hline Cochoeira et al (2012) & 7.3 \\
\hline Philippo et al (2008) & 8.8 \\
\hline Kullman et al (1996) & 19 \\
\hline
\end{tabular}


Hence, it is recommended that surgeons properly identify the EHBT anatomy intraoperatively in order to avoid injuries. To our knowledge, there are very few studies in the existing literature that looked at the association between abnormal anatomy of extrahepatic biliary tree and genders. According to this study, the association seems to be statistically insignificant $(\mathrm{p}>0.05)$.

The key abnormalities found in gall bladder were flask shaped gall bladder in 5\% subjects and cylindrical shapedGB in $2 \%$ subjects. A similar proportion (2.86\%) of cylindrical shaped GB and $2.86 \%$ of Flask shaped GB was observed by Nadeem et al (68) in UAE; and van Eijick et al, found a very high prevalence of Hartmann's pouch $(52 \%)$ in their study ${ }^{(69)}$.

Percentages of cystic artery variations including cystic artery having prominent anterior branch, cystic artery having prominent posterior branch,cystic artery outside Calot's triangle and cystic arteryarising from common hepatic artery occured more frequent in female population as compared to males. This distribution pattern is very nearer to one reported in an earlier study (75).

Table 2: Comparison of Cystic Artery Variations:

\begin{tabular}{|l|c|c|c|c|c|c|}
\hline Studies: & $\begin{array}{c}\text { Present } \\
\text { Study }\end{array}$ & $\begin{array}{c}\text { Marona et al } \\
(\mathbf{2 0 1 9 )}\end{array}$ & $\begin{array}{c}\text { Andall et al } \\
(\mathbf{2 0 1 6 )}\end{array}$ & $\begin{array}{c}\text { Kamath } \\
\mathbf{( 2 0 1 6 )}\end{array}$ & Lutfi (2013) & Khamiso (2010) \\
\hline $\begin{array}{l}\text { Prominent Anterior } \\
\text { branch (\%) }\end{array}$ & 2.5 & - & 5.4 & - & 16 & 2.67 \\
\hline $\begin{array}{l}\text { Accessory Cystic } \\
\text { Artery (\%) }\end{array}$ & 1 & - & - & - & 18 & 1 \\
\hline $\begin{array}{l}\text { Moynihan's hump } \\
\text { (\%) }\end{array}$ & 0.5 & 1.3 & - & 5 & - & \\
\hline
\end{tabular}

The present study found cystic artery having an abnormal course division in $4 \%$ of the subjects. It requires a thorough understanding of the intra- and extra-hepatic anatomical relationships between the portal vein,hepatic artery, biliary tract, and hepatic vein, and also their respective contributions to liver physiology ${ }^{(78)}$.

\section{Conclusion}

Main findings of current study confirmed that the detailed information of the boundaries and contents of hepatobiliary triangle and its variable ductal and vascular patterns is of huge significance for the diagnostic and therapeutic success as it makes surgical approaches more focused and technically perfect.
Ethical Clearance- Taken from ethical committee of institute

\section{Source of Funding- Self}

Conflict of Interest $-\mathrm{Nil}$

\section{References}

1. Tendon R. Diseases of gallbladder and biliary tract. API textbook of medicine. 7th ed, 2003, PP 642-44.

2. Conference NC. Gallstones and laparoscopic cholecystectomy: JAMA 1992; 269: 1018-24.

3. Chari RS, Shah SA. Biliary system, Sabiston textbook of surgery; Courtney M Townsend, R Laniel Beauchamp, B. Mark Evers, Kenneth L Mattox. 18th edn, Saunders Elsevier, vol 2, 2009. 
chapter 54, PP: 1547-1588.

4. Stewart L, Oesterle AL, Erdan I, et al. Pathogenesis of pigment gallstones in western societies: The central role of bacteria. J Gastroinfest Surg 2002; 6: 891-903.

5. Sharma SK, Thapa PB, Pandey A, Kayestha B, Poudyal S. Predicting difficulties during laparoscopic cholecystectomy by preoperative ultrasound. Kathmandu University Medical Journal 2007; 5(17): 8-11

6. Mouret P. How I developed laparoscopic cholecystectomy. Ann Acad Med Singapore, 1996 Sep.

7. Strasberg SM, Hertl M, Soper NJ. An analysis of the problemof biliary injury during laparoscopic cholecystectomy. Journal of the American College of Surgeons, vol. 180, no. 1, pp.

8. Johnston MJ, Fitzgerald JE Outpatient management of biliary colic: a prospective observational study of prescribing habits and analgesia effectiveness. International Journal of Surgery 2014;12:169-176

9. Polguj M,PodgorskiM, Hogendorf P, TopolM. Variations of the hepatobiliary vasculature including coexistence of accessory right hepatic artery with unusuallyarisingdoublecysticarteries: Case report and literature review. Anatomical Science International. 2014;89(3):195-198

10. Benson EA, Page RE. A practical reappraisal of the anatomy of the extrahepatic bile ducts and arteries. Br J Surg. 1976; 63:853-60. 6. Hand BH. Anatomy and function of the extrahepatic biliary system. Clin Gastroenterol. 1973; 2:3-29.

11. Ding YM, Wang B, Wang WX, Wang P, Yan JS. New classification of the anatomic variations of cystic artery during laparoscopic cholecystectomy. World Journal of Gastroenterology. 2007;13(42):5629-5634

12. Altaf K, Talpur H, Laghari A, et al. Anatomical variations and congenital anomalies of extra hepatic biliary system encountered during laparoscopic cholecystectomy. JPMA. 2010; 60(2):89-93.

13. Chari RS, Shah SA. Biliary system, Sabiston textbook of surgery; Courtney M Townsend, R Laniel Beauchamp, B. Mark Evers, Kenneth L
Mattox. 18th edn, Saunders Elsevier, vol 2, 2009. chapter 54, PP: 1547-1588

14. Bailey HH, Love RJ. Short practice of surgery. $27^{\text {th }}$ ed: Florida: CRC Press; 2018. 1188-1189 p.

15. Conference NC. Gallstones and laparoscopic cholecystectomy: JAMA 1992; 269: 1018-24.

16. Tendon R. Diseases of gallbladder and biliary tract. API textbook of medicine. 7th ed, 2003, PP 64244.

17. Seiler C, Glattly A, Metzger A, Czerniak A. Injuries to the diaphragm and its repair during laparoscopic cholecystectomy. Surg Endosc 1995; 9: 193-4.

18. Way L W, Stewart L, Gantert W, et al. Causes and prevention of laparoscopic bile duct injuries: analysis of 252 cases from a human factors and cognitive psychology perspective. Ann Surg 2003; 4:460.

19. Higgins PM, Eadie DG. Herniation through the foramen of Winslow. Ann Surg. 1965;161(4):592596.

20. Numata K, Kunishi Y, Kurakami Y, Tsuchida K, Yoshida T, Osaragi T, et al. Gallbladder herniation into the lesser sac through the foramen of Winslow: report of a case. Surg Today.2013;43:1194-1198.

21. Everhart JE, Yeh F, Lee ET, et al. Prevalence of gallbladder disease in American Indian populations: findings from the Strong Heart Study. HepatolBaltim Md. 2002; 35(6): 1507-12

22. Mallon P, White J, McMenamin M, Das N, Hughes $\mathrm{D}$, Gilliland R. Increased cholecystectomy rate in the laparoscopic era: a study of the potential causative factors. Surg Endosc. 2006;20(6):883-6

23. Gurusamy KS, Koti R, Fusai G, Davidson BR. Early versus delayed laparoscopic cholecystectomy for uncomplicated biliary colic. Cochrane Database Syst Rev. 2013;6:CD007196

24. Gutt CN, Encke J, Köninger J, Harnoss J-C, Weigand K, Kipfmüller K, et al. Acute cholecystitis: early versus delayed cholecystectomy, a multicenter randomized trial (ACDC study, NCT00447304). Ann Surg. 2013;258(3):385-93

25. Germanos S, Gourgiotis S, Kocher HM. Clinical update: early surgery for acute cholecystitis. Lancet. 2007;369(9575):1774-6 
26. Wanjura V, Lundström P, Osterberg J, Rasmussen I, Karlson B-M, Sandblom G. Gastrointestinal quality-of-life after cholecystectomy: indication predicts gastrointestinal symptoms and abdominal pain. World J Surg. 2014;38(12):3075-81. 